\title{
Night optimised care technology for users needing assisted lifestyles
}

\author{
J. Augusto ${ }^{a * \dagger}$, M. Mulvenna ${ }^{\mathrm{a}}$, H. Zheng ${ }^{\mathrm{a}}$, H. Wang ${ }^{\mathrm{a}}$, S. Martin ${ }^{\mathrm{b}}$, P. McCullagh ${ }^{\mathrm{a}}$ and J. Wallace ${ }^{\mathrm{a}}$ \\ ${ }^{a}$ School of Computer Science and Mathematics, University of Ulster, Newtownabbey BT37 0QB, UK; ${ }^{b}$ School of Health Sciences, \\ University of Ulster, Newtownabbey BT37 OQB, UK
}

(Received 23 October 2012; final version received 11 June 2013)

\begin{abstract}
There is growing interest in the development of ambient assisted living services to increase the quality of life of the increasing proportion of the older population. We report on the Night Optimised Care Technology for UseRs Needing Assisted Lifestyles project, which provides specialised night time support to people at early stages of dementia. This article explains the technical infrastructure, the intelligent software behind the decision-making driving the system, the software development process followed, the interfaces used to interact with the user, and the findings and lessons of our user-centred approach.
\end{abstract}

Keywords: ambient assisted living; sensing; software engineering; user-centred design

\section{Introduction}

In the countries of the UK, healthcare reforms have placed a renewed emphasis on the delivery of primary care, with a focus on prevention and wellbeing. This updated approach to care has been mirrored in many countries in the developed world. Assisted living systems can support the shift of care from the secondary/tertiary care hospital to the client's own home.

There are clear indicators that the proportion of older adults in the population is increasing: by 2035 the number of people aged 85 and over is projected to be almost 2.5 times larger than in 2010, reaching 3.5 million and accounting for $5 \%$ of the total population. The population aged 65 and over will account for $23 \%$ of the total population in 2035 , whilst the proportion of the population aged between 16 and 64 is due to fall from $65 \%$ to $59 \%$ (UK National Statistics Guide to Older People 2012). As this process unfolds, it is important that such solutions are embraced within the healthcare service delivery pathways. This remains a significant organisational challenge, in addition there may be a significant market opportunity for suppliers to deliver ambient assisted living (AAL) applications (Augusto et al. 2012). Such applications require technology (both hardware and software) which is reliable, stable, minimally intrusive and easy to use.

In 2011, Northern Ireland's government signed a six year contract for telehealth technology, covering patients with heart and respiratory conditions, diabetes and those who have suffered a stroke (Sade Laja 2012). Health Minister Michael McGimpsey said the pressure on the country's health budget meant that the service will have to find new ways of ensuring the delivery of a high quality service.

He stated:

With increasing numbers of people presenting with more and more complex needs and extremely high expectations of the health service, we must continue to provide the highest possible standard of care. There is no doubt that remote telemonitoring is a prime example of the innovation that will be required going forward.

Initial results from the UK's Telehealth Whole System Demonstrator programme showed that, if delivered properly, telehealth can substantially lower the number of bed days spent in hospital and reduce mortality, the need for admissions to hospital and the time spent in Accident \& Emergency Departments (Department of Health Whole System Demonstrator Programme: Headline Findings 2011). Indeed, cost saving is a major political and economic driver for telehealth (Limb 2012). In addition to the technology push, there is growing interest in assistive technology from the medical community (Daniel et al. 2009). As always, with the introduction of new technology and the resultant changes in the healthcare organisation, timing is a contentious issue. For example, in a recent article in the British Medical Journal, Gornall questioned whether such changes are premature, citing the need for more time for evaluation (Gornall 2012).

Whilst telehealth solutions for long-term conditions such as chronic obstructive pulmonary disease and heart disease has received attention (Car 2012), less work has been undertaken in the area of assistive technology for dementia care. This type of assistive technology is normally defined as 'telecare'. In Kerr et al. (2010) the following definition is provided: 'Telecare is used to describe the use of equipment 
within and out-with the home to monitor changing needs and risks, and to provide alerts and information that enable improved and informed responses to those needs and risks.'

It is estimated that 10 million people across Europe and 35.6 million people worldwide have dementia (Prince and Jackson 2010). In the USA, the Alzheimers' Association (Alzheimer's Society 2011) estimates that each year 60\% of people with Alzheimer's display symptoms of wandering; feeling compelled to walk and/or leave the home. Such wandering increases the possibility of falling (Kerr and Murray 2011) and this has associated often significant complications for older people. In addition, sleep disturbance is a major issue affecting both the dementia sufferer and carer (Koenig et al. 2008, Rowe et al. 2010). Technology is becoming available to address these issues but question on its effectiveness and usability and hence potential benefit remain.

Most of the contributions reported in the technical literature focus on the daylight period of the day. Night Optimised Care Technology for UseRs Needing Assisted Lifestyles (NOCTURNAL) specifically addresses the needs of the person with early stage dementia during the night period (McCullagh et al. 2009). The environment at night can be perceived very differently and disorientation is more likely for a person with dementia due to a number of factors, e.g. low light conditions. A person with dementia is also more likely to be confused and disorientated on awakening (Scarmeas et al. 2007). Older people may also experience altered and irregular sleeping patterns. This includes fragmented sleep patterns, insomnia and sleep apnoea. The latter is 'increasingly seen amongst older people and is significantly associated with cardio- and cerebrovascular disease as well as cognitive impairment' (Wolkove et al. 2007). People with dementia may also be likely to move around their home at night causing distress to themselves and their carers (Hermans et al. 2007). Finally, at night time a person with dementia may not have as timely access to carers as during the daytime. Technology can play a supporting role providing assistance to people with dementia during night time (Carswell et al. 2009). The NOCTURNAL project enhanced night time care offer of our care provider partner ${ }^{1}$ in a more holistic way: it provides night care using several different technologies, in several places of the house to check on different elements of night time care. This article provides an all rounded view of the project which amalgamated a number of new concepts in order to provide an innovative solution to a problem not well addressed before. Our system was guided by user-centred design (UCD) (Section 2) which we considered an essential feature to make sure the final product was meaningful to the intended end users. The system that the project was aiming to create was autonomous and intelligent, and its behaviour was guided by a multi-agent system implementing the concept of context-awareness (Section 3). The organisation of the group of agents is novel for multi-agent systems deployed in AAL systems. The project was also innovative in considering the system as a type of safety-critical system and used principles of rigorous software engineering which have not been applied in this area before (Section 4). In addition to monitoring and controlling of the environment in a way which is helpful to the person being assisted, the system also provided useful information on the behaviour of the person which can be made available to the caring team (for example, social workers and doctors, in some cases to relatives as well). Hence, part of the efforts of the project addressed data visualisation (Section 5) in a way which can be interpreted by some of the stakeholders of the system and be useful to benefit the care of the person being assisted. We also explain the validation of the system underwent being tested and assessed by real users fulfilling the criteria of intended beneficiaries of the system developed (Section 6).

\section{User-centred design}

UCD is an approach that puts the customer or user at the centre of the design process (Rubin 1994). UCD has been successfully used in many product designs and is supported by standards (ISO-13407 1999). The key aim in UCD is to learn what product or service is best suited to meet the needs of the user, and the intended benefit arising from the application of the approach is better usable in the resulting designed product or service. There is a long tradition of user-orientated, experience-based approaches developed to realise these aims and benefits, including user experience (Norman et al. 1995), contextual design (Beyer and Holtzblatt 1998), action research (Lewin 1946) and cooperative (participatory) design (Bødker et al. 1993). The NOCTURNAL project employed UCD process to assist in gathering requirements.

\subsection{Gathering requirements}

Research on the use of information and communication technologies to address the needs of people with dementia during daytime has increased in the last few years (Adlam et al. 2004, Davies et al. 2009). However, the needs of people with dementia at night time have not received a similar degree of research despite their needs being at least as important (Carswell et al. 2009).

The person with dementia may have a much more pronounced and immediate need for help and support as they awake in an unknown, dark environment. Whilst not an emergency, the sensors and actuators must be capable of quickly creating an intervention that moderates the anxiety of the person with dementia. During night time, the actuators have to manage the lighting for the person with dementia in particular to provide illumination and lighted guidance to the bathroom and back. In addition to light, sound can play a more important role during night time. In particular, the use of music as a therapeutic intervention has been shown to reduce anxiety of people with dementia (Aldridge 2000). Light and music together can provide 
a powerful intervention capability, and it has been shown that there is a significant reduction in restlessness immediately after people with dementia in care homes experienced multi-sensory environments through the use of lighting, tactile surfaces, meditative music and the odour of essential oils (Robinson et al. 2006). The Joseph Rowntree Foundation report (Kerr et al. 2008) made recommendations for home management of older people. These recommendations were to ensure that, where appropriate, relevant technology should be used, for example, guidance around noise, light, safety, silent call system, as well as to ensure that systems are in place for night staff to have all the equipment and facilities required to provide good night time care.

The difficult facet of user engagement in this research was gaining access to people with dementia and their carers. Whilst access to this constituency of people was facilitated by the local health trusts in Northern Ireland, not many people met the criteria in terms of their home situation, stage of disease or other factors. Consequently, the methods to be used in the work, by necessity, had to be qualitative in nature, focusing on individual home meetings with the people with dementia and their carers. Such personorientated methods naturally suit engagement with people with dementia where it is important for the participants (person with dementia, carers and general family) to feel relaxed and comfortable. The project team also had a series of informal meetings with representatives of health and social care organisations to gather their views on the features the system should have and also on how to approach the home visits. The requirements gathered from the home visits were used to specify a suite of supporting interventions made available in the NOCTURNAL system, encompassing:

- Audio activity - music and the spoken word.

- Visual activity - images displayed on a bedside device.

- Combined audio/visual activity - audio and image available on a bedside device.

- Sequenced lighting guidance - turning on and off house lights to guide the client to the toilet/bathroom and back.

Audio and visual therapies can be used to support temporal awareness and the lighting guidance can be used to help ameliorate disorientation. It is very difficult to induce sleep by an external agent so the focus of the interventions was towards reducing the level of arousal as much as possible when a disturbance occurs.

\subsection{Interfaces}

AAL services have benefited from advances in sensor technology, hardware, software and communication paradigms to such an extent that AAL services have gained market penetration into the home, work and health environments. AAL may be implemented to either replace or complement the care provided by the carer. As technology becomes increasingly mobile, ubiquitous and pervasive, it is of course likely that the wider population will become beneficiaries of AAL and may lead an increasingly technology-augmented lifestyle.

AAL technologies have been outlined as technologies that may help to extend the time that older people can live at home by 'increasing their autonomy and assisting them in carrying out activities of daily life' (Wojciechowski and Xiong 2008). The services that AAL technologies may use include functional, activity, cognitive, intellectual and sensory support. Examples of functions that the AAL technologies may provide include alarms to detect dangerous situations that are a threat to the user's health and safety, monitoring and continuously checking the health and well being of the user and the use of interactive and virtual services to help support the user. AAL technologies may also be used for communication, enabling the user to keep in touch with family, friends and carers, and for example, in support of reminiscing.

AAL services have to support very different kinds of technologies encompassing sensors, actuators, communication hubs and interfaces. There are a number of different classes of users of the services. In essence, AAL services utilise data and information from these devices using different protocols, and orchestrate this information for the different users. The primary user of AAL services is the care recipient, but there are other important users including on-site formal carers, off-site telecarers or monitors of AAL services, informal carers (including family, neighbours and friends) and those in charge of maintaining the quality of service in a technical service provision. Each of these classes of users has a role or roles to play in AAL service provision and its use (see Table 1).

AAL services have evolved from relatively simple telecare services such as emergency fall alarm provision into more sophisticated telehealth services supporting people with long-term chronic health conditions such as Alzheimer's disease, in the assessment of their symptoms. Q1 In this evolution, the data generated has increased in volume and complexity. The task of interpreting the meaning in the data relating to the wellbeing and health of the care recipient has also become increasingly more complex and the diverse range of types of user and their overlapping roles in AAL service provision and efficacy have increased markedly.

In determining appropriate AAL services, understanding the behaviour of the care recipients in terms of their activities of daily living (ADL) is of particular value. For example, probabilistic models have been used to manage uncertainty and incompleteness of data as the ADLs are undertaken. ADLs comprise common activities such as making tea and using the telephone. Conveying the information through visualisation of such activities is much easier for a carer to interpret and comprehend compared 
Table 1. AAL service users and their roles.

\begin{tabular}{|c|c|}
\hline User & Role \\
\hline Care recipient & $\begin{array}{l}\text { User of the services; needs to be able } \\
\text { to interact with the services to gain } \\
\text { assistance to provide feedback where } \\
\text { needed }\end{array}$ \\
\hline $\begin{array}{l}\text { Formal carers } \\
\text { on-site }\end{array}$ & $\begin{array}{l}\text { Interacts with the services in tandem } \\
\text { with the care recipient to assess } \\
\text { progress in care regime; interacts } \\
\text { to add information into system, } \\
\text { for example, to add medication } \\
\text { reminders }\end{array}$ \\
\hline $\begin{array}{l}\text { Formal carers } \\
\text { off-site }\end{array}$ & $\begin{array}{l}\text { As above for formal carers on-site but } \\
\text { may also interact remotely to update } \\
\text { information and interact with services } \\
\text { that measure or provide care to more } \\
\text { than one home }\end{array}$ \\
\hline $\begin{array}{l}\text { Telecare/telehealth } \\
\text { monitors off-site }\end{array}$ & $\begin{array}{l}\text { Managing remote care provision; } \\
\text { providing care triage in decision } \\
\text { support for interventions; monitoring } \\
\text { relatively large numbers of care } \\
\text { recipients }\end{array}$ \\
\hline $\begin{array}{l}\text { Informal carers } \\
\text { on-site }\end{array}$ & $\begin{array}{l}\text { Accessing information on health and } \\
\text { wellbeing of care recipient; working } \\
\text { with care recipient to understand } \\
\text { health and wellbeing of care recipient } \\
\text { and communicate to care recipient }\end{array}$ \\
\hline $\begin{array}{l}\text { Informal carers } \\
\text { off-site }\end{array}$ & $\begin{array}{l}\text { Remote access to monitor key } \\
\text { information on care recipient, for } \\
\text { example, family member concerned } \\
\text { about quality of life of care recipient }\end{array}$ \\
\hline $\begin{array}{l}\text { Technical } \\
\text { maintenance }\end{array}$ & $\begin{array}{l}\text { Deploying tools to assess quality of data } \\
\text { being gathered, decision support and } \\
\text { reporting on metrics from homes of } \\
\text { care recipients; detection of errors }\end{array}$ \\
\hline
\end{tabular}

with data-rich, lower-level data about movement within a room, for example. However, incorrect ADL identification has the potential to introduce more significant errors which could be harmful or even life threatening for the care recipient.

There is a need for the AAL services to communicate vitally important information in an easy-to-understand manner to all users whilst maintaining the privacy of the care recipient and their informal carers. The manner in which these AAL services communicate information draws heavily on visualisation techniques. The most important user, the recipient of AAL care services, is more likely to be someone who is not familiar with computers in general and this is a major complicating factor in the successful provision of visualisation of data and information in AAL services.

Data collected in AAL services can include movement information, used to (i) alert an emergency incident such as a fall; (ii) alert for unexpected behaviours, such as an older person going out late at night; (iii) remind and assist daily living activities, such as doing physical activities and taking medications. The AAL services store personal activity profiles over periods of time. The trend of user behaviour and the pattern of user activity events provide rich information in the analysis of care recipients' behaviour patterns.

Visualisation of information for AAL systems needs adaptive interfaces that target specific needs and preferences of the recipients of care services. We may refer to this as user-awareness, but overall this type of knowledge that the system uses to deliver a more useful service can be considered part of the wider term of context-awareness. For example, for the person being cared for different reminders may be suitable in the morning (e.g. 'time to take your medicine' and 'you did not have breakfast yet') than in the afternoon (e.g. 'you did not have lunch yet'). Day and night require different types of content given that the person it is delivered to may have different level of consciousness and alertness. It is also expected that the messages to be delivered during the night will be focused on sustaining a healthy sleeping pattern whilst during the day it could refer to many other daily activities. The place of the house where a reminder has to be delivered can make a difference as well (e.g. kitchen or living room displays may be assumed to be used with normal levels of lighting whilst those in the bedroom which may be mostly used with low lighting or darkness).

\subsubsection{Interface design for NOCTURNAL}

It is evident that there is currently a gap with regards to the supply of a fully functional, dependable and appropriate visualisation of relevant service data, particularly with regards to the different user types and roles of people involved in the delivery of care. There is a need to design applications, which display AAL service data in a meaningful, holistic yet concise manner. Identifying the needs for each user group and how these needs are provided both physically and visually has to be resolved if AAL services are going to be utilised more fully in society. Gil et al. (2007) suggest that the focus of visual representation should concentrate on living aspects that are regular, e.g. sleeping and eating, and have a relationship with wellbeing.

A key requirement for AAL services is to minimise the cognitive overhead required to interpret information, by presenting normal behaviours and patterns in the most succinct form possible, and highlighting abnormal behaviours and alarm states tailored to each end user group's needs. The work by Consolvo et al. (2008) on visual metaphors that requires minimal cognitive processing by the users is promising and indicates possible development pathways that communicate regular behaviours and useful feedback to care recipients and their informal carers.

After assessing the different users for the project, it is clear that there are two key types of users, the care recipient, and those who need summary information on behaviour across time and location (within the home of the care recipient). 

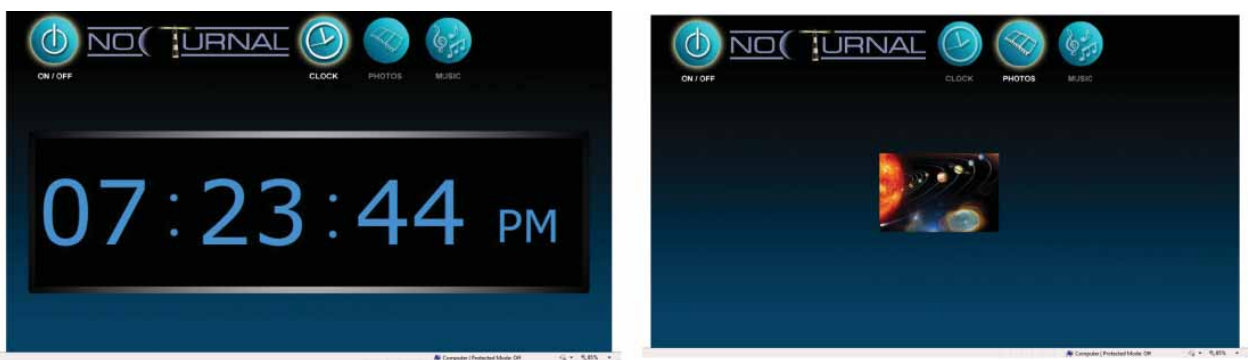

Figure 1. Bed side interface in default clock mode (left) and then once the photo button has been touched (right).

\subsubsection{Interface design for the care recipient}

The interface for the care recipient is presented via a touch screen device at the bedside. This interface has the following roles:

- Playing music or audio messages.

- Showing images, photographs or video messages.

- Enabling interactivity using the touch screen.

One design assumption is that the device should require minimal user interaction from the care recipient, for example to choose one of the few basic functions available or to start/stop sounds and/or images. If the care recipient does want to stop images and/or sounds, then they can touch anywhere on the screen and the screen should immediate fade and become inactive and any sounds playing should fade. This single touch should operate as a toggle, where touching the screen again can restart sounds and/or images. Figure 1 shows two screenshots of the interface for the care recipient. The design of this interface was informed by the initial workshop and by the first five users testing the early versions of the system in their houses.

\subsubsection{Interface design for the carer and others requiring summary information}

The three main decision support modes are communication of advice, provision of information and management of (nuances of) alarm escalation. In the first development phase the focus was on the provision of information. This was based upon the 'time-and-place' matrix common in many AAL systems and currently in place for NOCTURNAL. The benefit of this type of interface is the ability to cross reference alarm events with the location and time of day and thus verify if the sensor event is a probable error or is a true reflection of what has happened. The difficulty with such an interface, however, is that it does present a cognitive overhead in processing it and requires expert guidance in order to understand it at first. It is particularly difficult for carers to decode the meaning of the graphs and charts. One possibility is to provide an automatically generated narrative describing the behaviour of the care recipient. This would be of most use to the carer, but may also be of value to the care recipient.

\subsection{Technical infrastructure}

The project was aimed to extend and innovate on the services offered by the partner company in the project. As such the project evolved the final product through a series of stages of increasing independence from the market products. The first phase started with the implementation of the idea based on the ADLife commercial product produced by Tunstall and used up to that point by the partner company. This worked well for the monitoring phase of the project when we only needed to historically review the data over an extended time frame. However, the system was not suitable for the next stage of the project when the system will be required to interact with the client on a near real-time basis and our team also needed to create new services given the commercial product was closed for developers outside its manufacturing company. The next version of the system was based in an entirely X10 (Brewer 2013) based platform which offered improvements on those two restrictions posed by the previous architecture. To overcome a limitation on the number of sensors and devices X10 systems can handle a third step was given to have a hybrid system where part of the sensing and actuation remained based on X10 (wired) and part of it with Zwave (wireless) (Brewer 2013). This Q2 final setting provided a balanced infrastructure in terms of capability and cost, an important dimension for the company to have possibilities to introduce this product in the market at an affordable price. More details of the technical infrastructure itself are available in McCullagh et al. (2010).

The current system provides a flexible platform able to respond rapidly to the environment it was installed in. The current design involves extensive learning from the previous phases and includes several features derived from the practical operation of the initial experiments. Some of the design rules applied during the system design included

- Where possible the software should be independent of the hardware.

- The software should be easily ported across platforms.

- The hardware should be standard 'off the shelf' and freely available.

- The system should be easy to install and remove with minimum modifications to the client's home. 
- It should be easy to access the data collected by the system from a remote location.

- The system should monitor its own performance and raise an alert when defined situations arise.

The current system meets these requirements and can be installed and removed quickly with the minimum of onsite setup or adjustments.

The software comprises the following user interface components:

- Care recipient interface - For the target user this has been kept very simple and intuitive to use. Functionality is limited to turning on and off the audio and visual therapies and adjusting some of their functions such as volume and selecting different tracks and images.

- Engineers interface - This is used to setup and adjust the system and gives full access to all functions including modifying the system. It is accessed by a secure method such as a password or function key combination. Can be accessed locally or remotely if an IP connection is available.

- Call centre interface - This is used by the call handler when a 'soft alarm' is raised by the system and will provide information on recent activity along with scripts and useful personal information to assist the call handler in assessing and controlling the situation for each individual. This information will be captured during the assessment and setup stage.

\section{Context-aware decision-making}

One of the important requirements for the NOCTURNAL system is that it has to be able to detect situations in real-time, decide based on the current context what, if any, actions should be taken and if an action is recommended then the system has to apply an intervention and monitor its progress. This requires the analysis of sensors and actuators in real-time and decisions to be made based on the behaviour of the client. Given the characteristics of the system we decided to organise the system as a hierarchy of specialised agents and given the nature of the application domain we decided to consider this as an instance of a safety-critical system (Augusto et al. 2011). This section explains how we organised the multiagent system and how we applied software engineering techniques to increase our reliability on the core software components.

The model of the overall architecture is depicted in Figure 2. Activities of the client trigger sensors which are recorded as events in a database. These events are fed to a group of monitoring agents specialised on night related situations (e.g. restlessness, bed occupancy and wandering). When the number of episodes of interest detected by any single agent is above an acceptable threshold, which is dynamically adapted to the client and the context, the agent involved contacts a Coordinating Agent which has a holistic view of the context informed by all the single agent's reports.

If appropriate, the Coordinating Agent can trigger a therapeutic intervention with the aim of helping the client. If

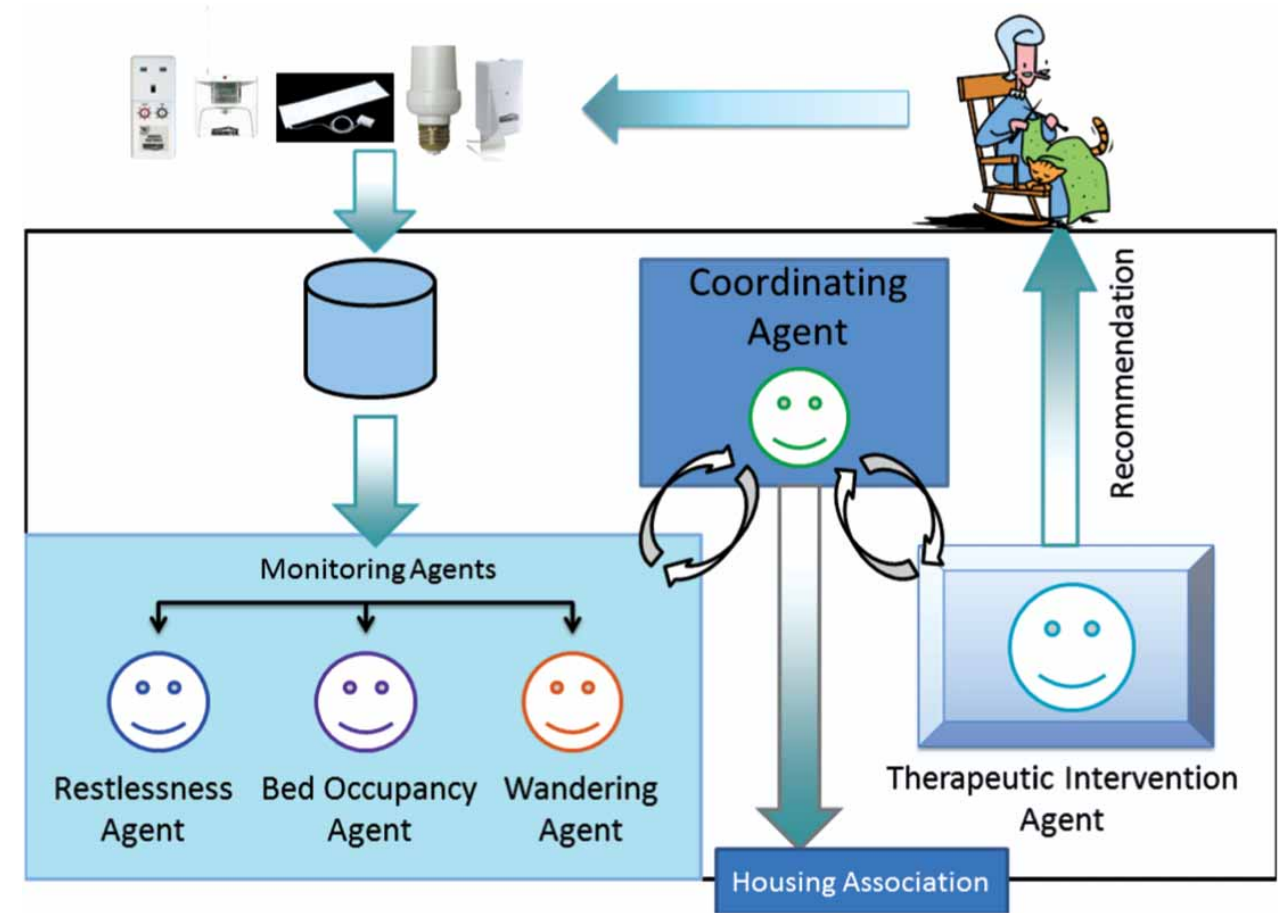




\begin{tabular}{|l|l|l|l|l|}
\hline House_ID & Sensor_type & Location & Event_type & Time_and_date \\
\hline House001 & PIR & Bedroom & on & $2011-07-0415: 04: 09$ \\
\hline House001 & PIR & Bedroom & on & $2011-07-0415: 04: 19$ \\
\hline House001 & PIR & Bedroom & on & $2011-07-0415: 04: 29$ \\
\hline House001 & PIR & Bedroom & on & $2011-07-0415: 04: 39$ \\
\hline House001 & PIR & Bedroom & on & $2011-07-0415: 04: 49$ \\
\hline House001 & PIR & Bedroom & on & $2011-07-0415: 04: 59$ \\
\hline House001 & PIR & Landing & on & $2011-07-0415: 05: 02$ \\
\hline House001 & PIR & Livingroom & on & $2011-07-0415: 05: 09$ \\
\hline House001 & PIR & Livingroom & on & $2011-07-0415: 05: 19$ \\
\hline House001 & PIR & Landing & on & $2011-07-0415: 05: 24$ \\
\hline House001 & PIR & Bedroom & on & $2011-07-0415: 05: 27$ \\
\hline House001 & Bed-chsir & Bedroom & on & $2011-07-0415: 05: 31$ \\
\hline House001 & Bed-chsir & Bedroom & off & $2011-07-0415: 05: 34$ \\
\hline House001 & Bed-chsir & Bedroom & on & $2011-07-0415: 05: 35$ \\
\hline House001 & Bed-chsir & Bedroom & off & $2011-07-0415: 05: 37$ \\
\hline House001 & PIR & Bedroom & on & $2011-07-0415: 05: 37$ \\
\hline House001 & Bed-chsir & Bedroom & on & $2011-07-0415: 05: 38$ \\
\hline
\end{tabular}

Figure 3. A log of sensor triggers.

subsequent reports from the monitoring agents show there are still reasons for concern the coordinating agent can issue a new intervention or eventually if the situation requires it the call centre at the Housing Association partner in our project can be contacted so that a human deals directly with the situation. The system then is used as a way to increase independence with safety at the same time it provides the Housing Association a way to optimise their resources as the system is capable to assist in some cases reducing the number of calls.

The system collects sensor data in a MySQL database which is then accessed by the agents in real-time. The agents access and transfer information as relevant according to their interests and specialisation. Figure 3 shows some of the databases used to collect the data received from the sensors. Figure 4 shows some of the databases used to log the inferences and decisions made by the agents.

\section{Software developing process}

The project considered the system as a type of safety-critical system and used principles of rigorous software engineering which have not been applied in this area before, but we firmly believe that it should be part of the standard development process used by development teams working in this area. Modelling and verification techniques were employed to inform and guide the development of our solution. Given that the system was organised as a group of distributed autonomous software agents, SPIN (Holzmann 2003) was selected as the main support tool. SPIN is one of the most well-known and used system for the verification of the software. It is a highly efficient and stable system with a user friendly interface and good team support. SPIN is focused on the concept of models. Software developers can model a system by using a language called Promela (PROcess MEta-LAnguage), which emphasises the role of processes and their interactions. Once a model has been created the possible scenarios represented in the model can be simulated in various ways (e.g. randomly guided by the machine or user guided). Additionally, software developers can use this tool to perform what in software engineering is called Formal Verification, i.e. an exhaustive analysis of the computations implied by the model. SPIN provides a formal language to specify system behaviour properties which can then be checked by the tool. If the property to be verified in the model does not hold, then SPIN provides a counter-example (an explanation of why that property is not true for that particular model). The presentation below is more centred on the model and the simulation process (see Augusto and McCullagh 2007, Augusto 2009 for an emphasis on verification of intelligent environments). 


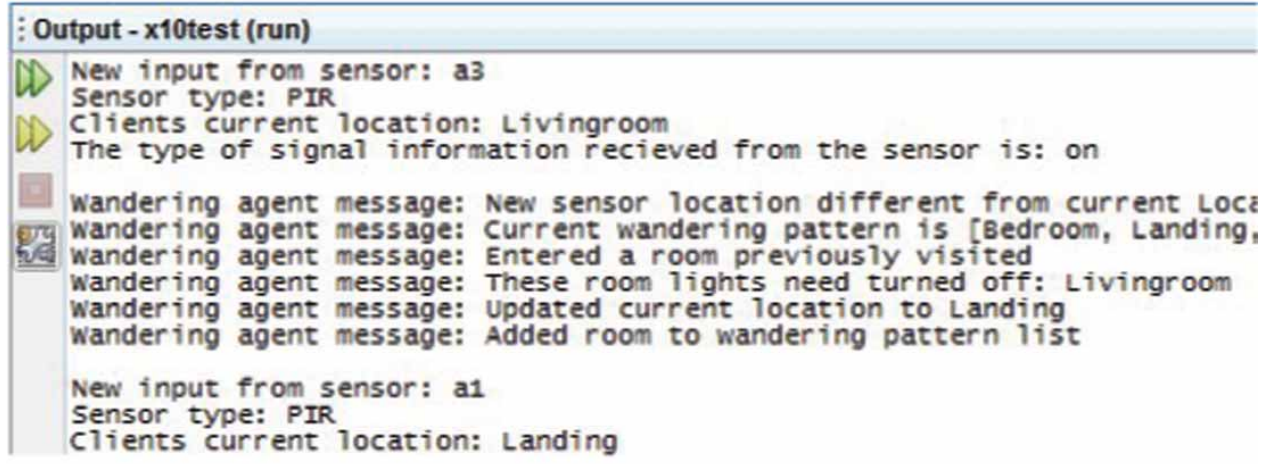

\section{Agent Results}

\begin{tabular}{|l|l|l|l|}
\hline House_ID & \multicolumn{1}{|c|}{ Activity } & \multicolumn{1}{c|}{ Result } & Time_and_date \\
\hline House001 & Actuation & [Bedroom and Bathroom light on] & 2011-07-04 15:04:10 \\
\hline House001 & Wandering & [The client has started wandering] & $2011-07-0415: 05: 02$ \\
\hline House001 & Wandering & [Entered the Landing] & 2011-07-04 15:05:02 \\
\hline House001 & Acutation & [Landing light on] & $2011-07-0415: 05: 03$ \\
\hline House001 & Wandering & [Entered the Livingroom] & $2011-07-0415: 05: 09$ \\
\hline House001 & Acutation & [Livingroom light on] & $2011-07-0415: 05: 09$ \\
\hline House001 & Wandering & [Entered the Landing] & $2011-07-0415: 05: 24$ \\
\hline House001 & Acutation & [Livingroom light off] & $2011-07-0415: 05: 25$ \\
\hline House001 & Wandering & [Entered the Bedroom] & $2011-07-0415: 05: 27$ \\
\hline House001 & Actuation & [Landing light off] & $2011-07-0415: 05: 28$ \\
\hline House001 & Bed Occupnacy & [The Client has returned to bed] & $2011-07-0415: 05: 32$ \\
\hline House001 & Wandering & [Bedroom, Landing, Livingroom, Landing, Bedroom] & $2011-07-0415: 05: 32$ \\
\hline House001 & Acutation & [Echo command to turn all lights off] & $2011-07-0415: 06: 32$ \\
\hline
\end{tabular}

Figure 4. A log of agent conclusions based on the primitive events obtained from networked sensors.

\subsection{Modelling}

Figure 2 depicted the main actors and interactions within the NOCTURNAL system agent-oriented architecture. The model was conceived to explicitly represent those elements and relationships and to use it as a framework to experiment with and discover non-trivial features which escaped the initial analysis of the team. One version of the model of the overall architecture is publicly available. ${ }^{2}$ Each main element of the technology and human actors depicted in Figure 2 is represented in the Promela model by a process type (each of them has their name highlighted in boldface).

Processes are autonomous entities running concurrently. Interaction amongst these elements is represented by message passing through synchronous channels. Naturally, there are many features of the model that can be changed to experiment with; this model is only a snapshot in the lifetime of the system.

\subsection{Simulation}

This model can be used for simulation in SPIN and several different types of views can be extracted as the simulation unfolds. Figure 5 shows a screenshot of iSPIN during a simulation of a model.

Figure 6 shows the content of the Message Sequence Chart in more detail depicting the different processes and the messages they sent each other in this specific random simulation.

The boxes at the top of Figure 6 indicate the name of the processes in the system. Arrows indicate a message sent from one process to another. The figure shows a run such that when process client activates a sensor this event is stored in the database and passed to the monitoring agents: restlessness, bed occupancy and wandering, they act according to whether it is relevant or not to them. For example in the first group of messages shown at the top of the figure, the agent dealing with bed occupancy is receiving relevant information but this does not trigger further consequences, whilst when the agent dealing with wandering is contacted it believes this merits contacting the coordinating agent. Something similar happens in the group of messages shown in the middle of the figure, but in this case the coordinating agent goes one level further as it believes the situation communicated by the bed 


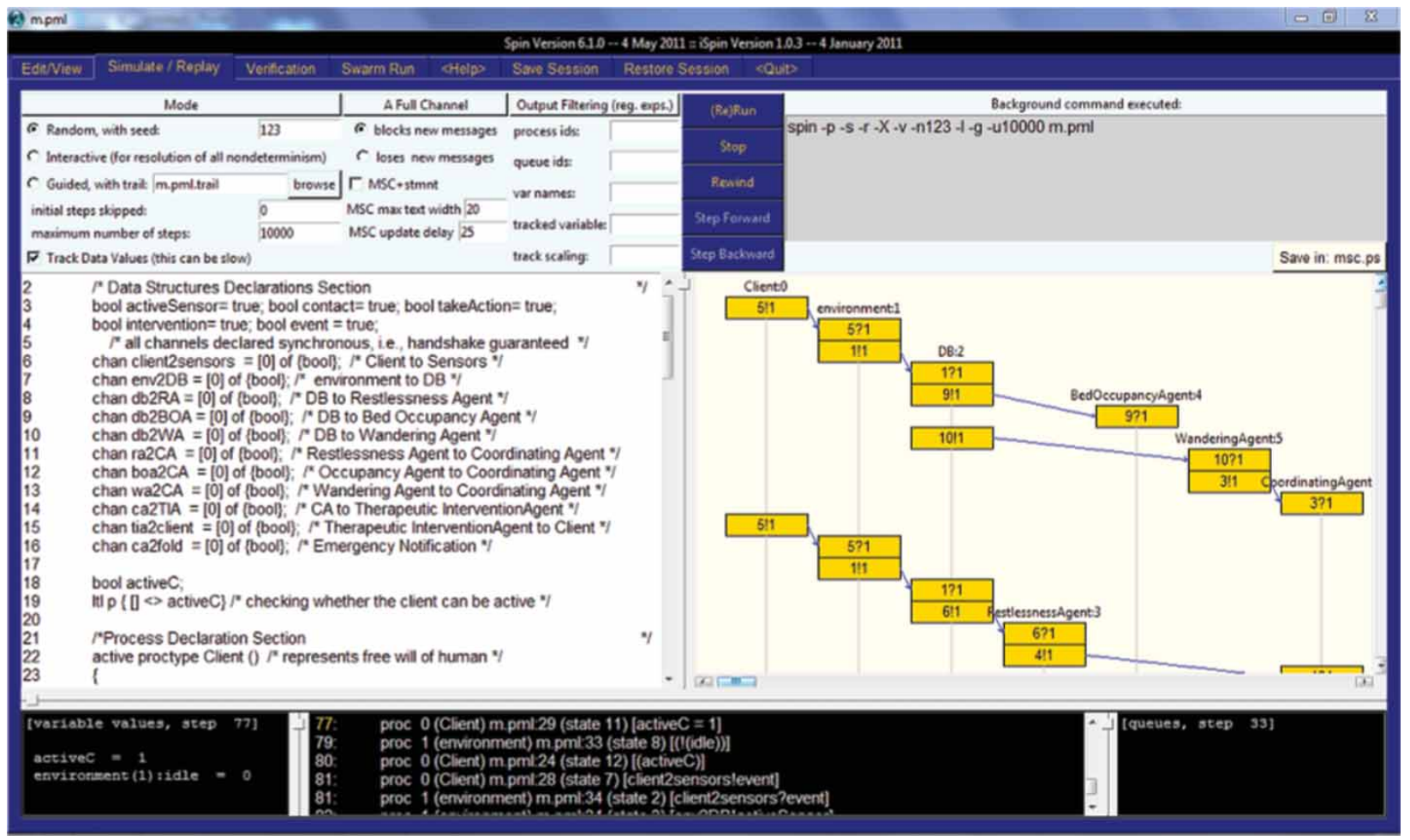

Figure 5. A simulation of one of the NOCTURNAL overall models. The left side of the panel shows part of the Promela model, the right hand side shows some of the interactions explored in a random simulation run, the lower panels (from left to right) show the effect on variables, the statements non-deterministically selected by SPIN for execution and the effect on channels.

occupancy agent requires intervention for which it contacts the agent managing therapeutic interventions. The groups of messages at the bottom of the figure shows a case where the coordinating agent has contacted the therapeutic intervention, this one has actuated in the environment but this has not improved the situation and the coordinating agent decides to contact the Housing Association (the service provider). Notice that this model does not focus on frequencies but rather on possibilities, i.e. whether something can be achieved or not within that architecture. Other modes we have explored focused on different aspects of the system, for example on how the monitoring agents can effectively keep track of the frequency of restlessness episodes, detect absence from bed or wandering, during a period of time.

\subsection{Verification}

Formally specified behavioural properties (e.g. [], <> and activeClient) can be explored using SPIN. These properties are usually related to the requirements of the system being examined. Examples of such properties for the NOCTURNAL case are: 'Can the system monitor the client continuously?', 'Are all sensor activations stored in the database', 'Is each emergency followed by a therapeutic intervention?'.

Figure 7 shows the result of running such a check for one of our models.

\section{Information visualisation}

A sleep (bed occupancy) pattern analysis and visualisation system, PAViS (Wang et al. 2010, Nikamalfard et al. 2011), are developed to support the night time monitoring. PAViS is implemented using Java. In this research, we define the sleep as being in bed for a reasonable long time, and the daily hours from 12.00 to the next day 12.00. Three types of sleep information: quantity, quality and rhythm are examined. The quantity of sleep is defined by the total amount of daily sleep time. The quality of overall sleep is measured using the number of sleep episodes, i.e. the number of sleep block (sleep-wake cycle) a client has during the $24 \mathrm{~h}$. We use the centre of the sleep starting time and sleep ending time (central-sleep-time) to monitor the sleep time rhythm or sleep habits. Readers are referred to Wang et al. (2010) for a detail description of these three measurements.

The following rules are applied to detect the sleep events:

(1) If (the bed sensor is 'in' AND not 'out' in less than $1 \mathrm{~min}$ ) AND (no other PIR ${ }^{3}$ activated), then the bed entry is valid.

(2) If (the bed sensor is 'out' AND NOT 'in' in less than a minute) AND (other PIR activated), then the bed out is valid.

(3) If the interval between to sleep block is less than 2 min, then merge the two blocks. 


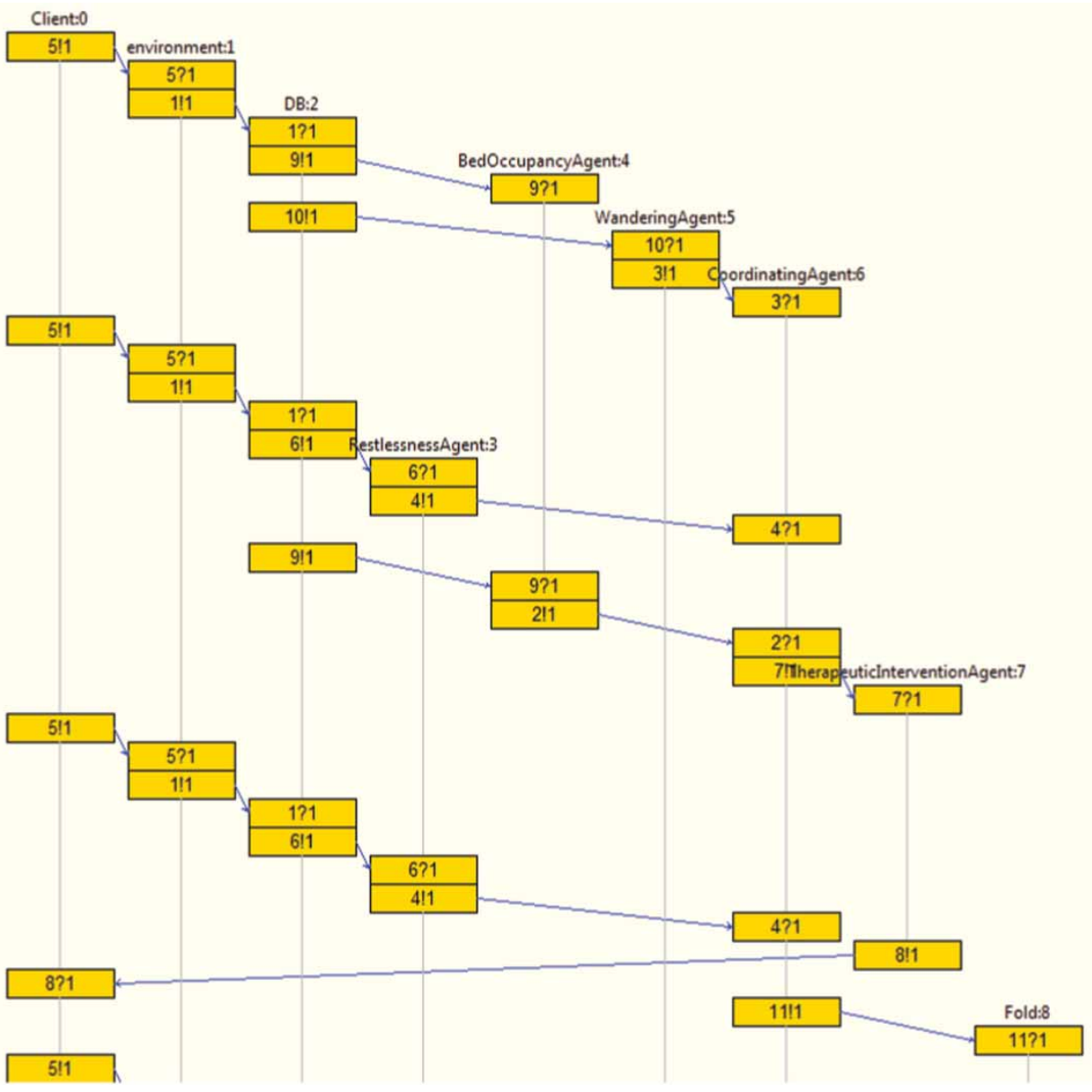

Figure 6. Processes of the overall architecture communicate with each other.

(4) On the day when the client was absent, the missing data in sleep episodes and the amount of total sleep time were replaced by the average values of the previous week to minimise alteration of overall statistics.

In this research, we provide several informative types of visual feedback on client's daily, weekly and monthly sleep information and profiles, including:

(1) Daily sleep pattern which displays a client's daily sleep - wake cycles.

(2) Weekly sleep pattern which includes:

(a) Client's daily sleep pattern over past seven days. This section enables convenient visual comparison of sleep patterns and detection of unusual days.

(b) Summary and trend of seven days of daily sleep-wake episodes.

(c) Summary and trend of seven days daily amount of sleep time.
(3) Monthly sleep pattern, which includes:

(a) Summary and trend of four weeks of daily sleep-wake episodes.

(b) Summary and trend of four weeks daily amount of sleep time.

These visual feedbacks reflect the quantity, quality and rhythm of the daily sleep pattern, and data can be selected over a chosen period of time (Figure 8). Three main functions are implemented to view: sleep patterns, sleep hours and sleep episodes on daily, weekly and monthly basis. Healthcare professionals can review clients' profiles and compare the changes of trend on various period of time, which may be helpful in determining the cognitive impairment stages.

To keep a consistent design theme different background colours are used, i.e. blue for daily information, green for weekly information and pink for monthly information (Figures 8-11). Figure 9 shows an example of one day's sleep pattern, although the client had good amount of sleep hours, there were four episodes observed, which indicate that the client had some sleep disturbances during the night. To find out if it was her normal pattern or abnormal pattern, 


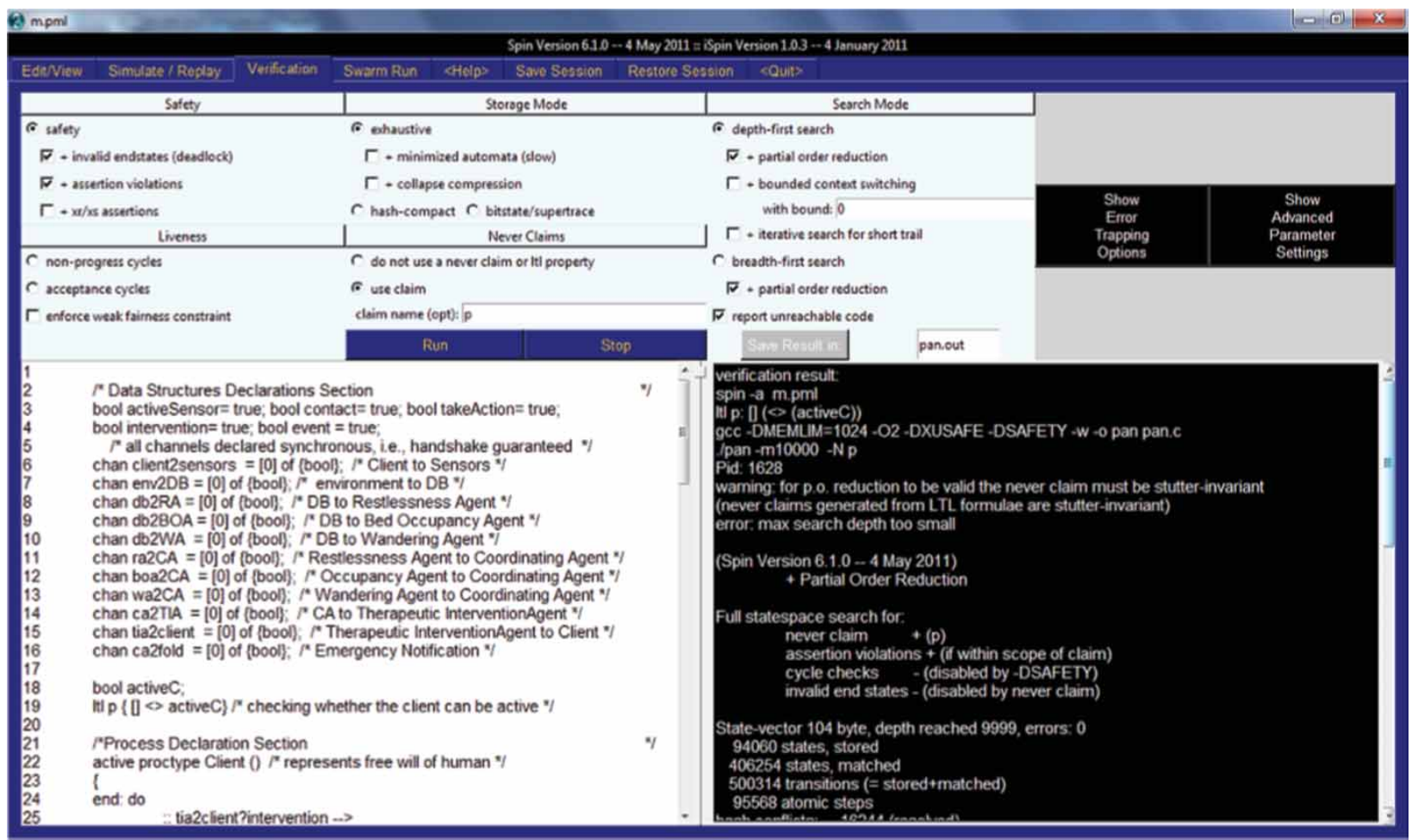

Figure 7. A verification of a requirement in relation to one of the NOCURNAL overall models. The left side of the panel shows part of the Promela model (including the property verified in line 19), the right hand side shows the statistics of the verification provided by SPIN, including the diagnosis that there were no errors (the property is consistent with the model).

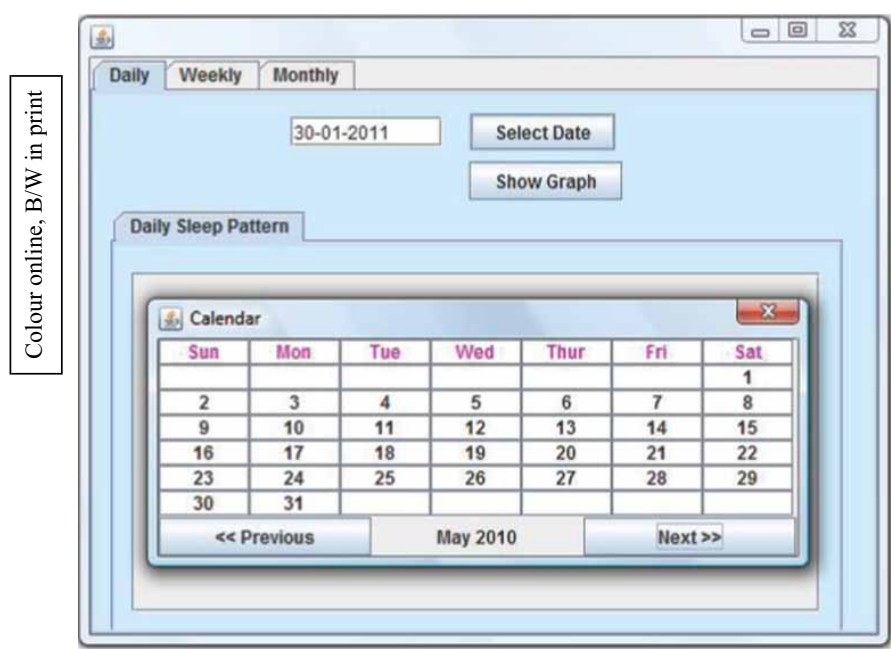

Figure 8. Calendar opens by pressing 'Select Date' button; after choosing desired date, the calendar closes and the selected date appears in the text $b$.

the viewer can use the weekly view to compare that date with previous dates (Figure 10), and the trend of changes. For example, the client had a good quality of sleep on 25 May (one sleep episode and $12 \mathrm{~h}$ of total sleep time) compared with four sleep episodes on the next day. Figure 11 shows a slight decrease in the total amount of sleep the client had in one month. There were two days where the total sleep hours dropped down to $7 \mathrm{~h}$.

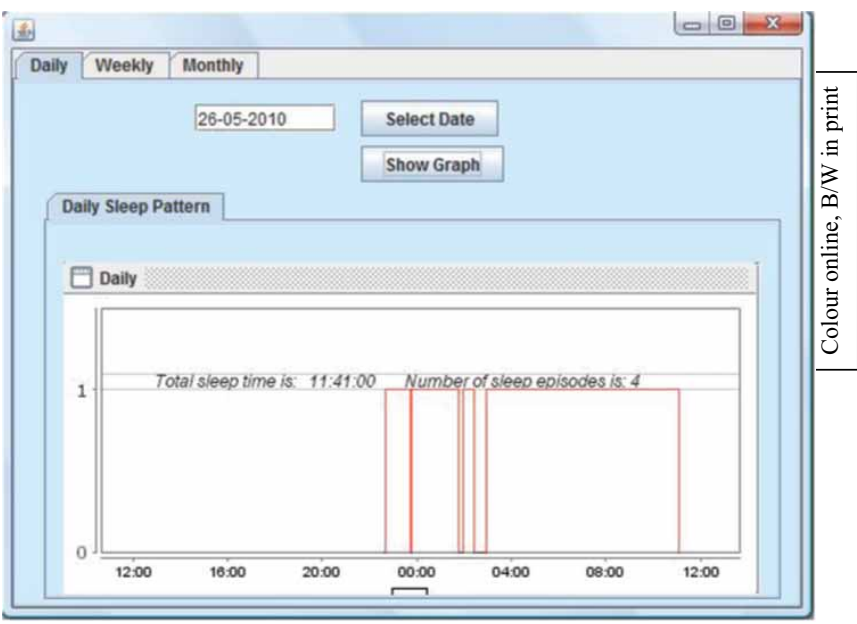

Figure 9. Summary of client's daily sleep pattern. The $x$-axis represents the time, from 12.00 o'clock to the next 12.00 o'clock. The $y$-axis indicates the sleep status: ' 0 ' is out of bed and ' 1 ' is in bed. Selected date are shown in text box. Total sleep hours and number of sleep episodes are shown above the graph.

\section{Validation}

The project requested opinions and feedbacks from different stakeholders at all stages of the development process. Protocols for this were developed and approved by the regional authority for ethical review (ORECNI). During the first few months of the project (initial requirement gathering phase) 


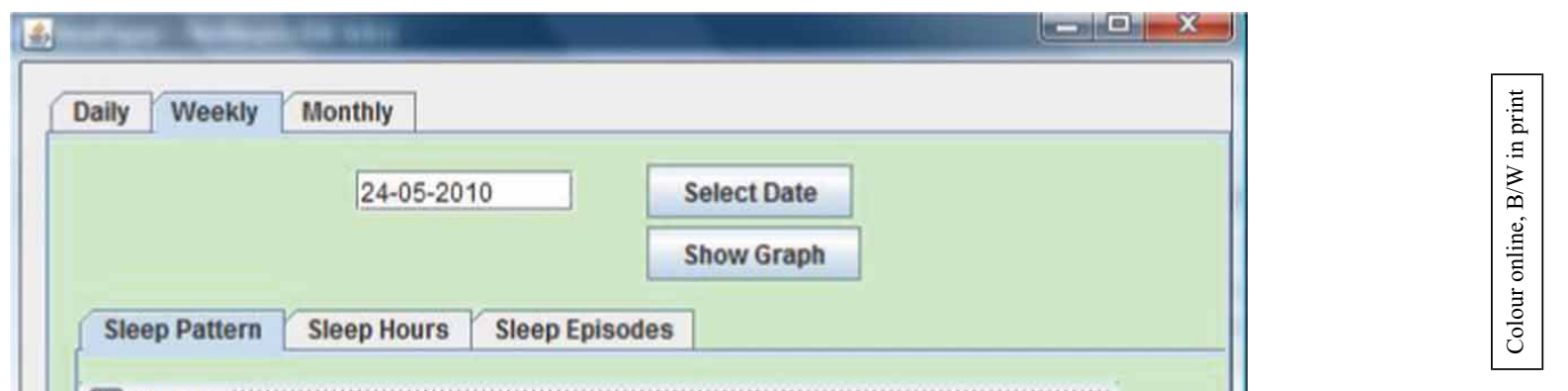

Weekly

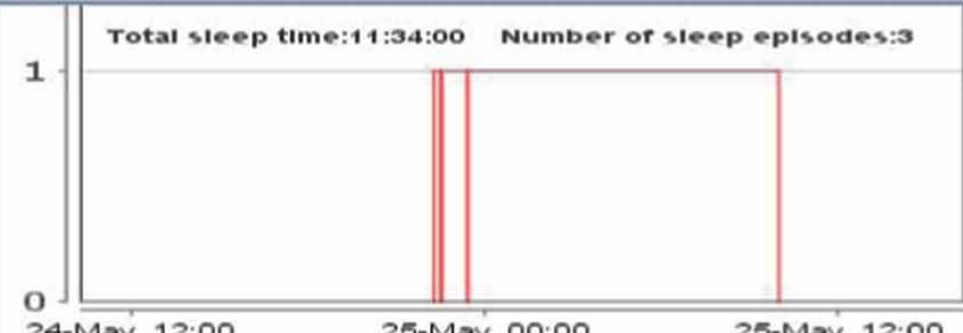

24-May, 12:00

25-May. 00:00

26-May, 12:00

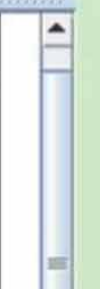

1391

1386

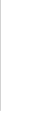

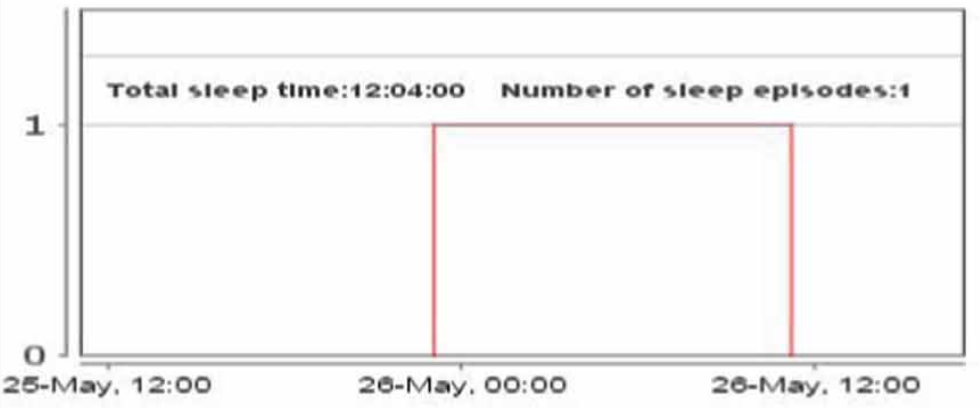

25-May, 12:00

20-May. 00:00

26-Mary. 12:00

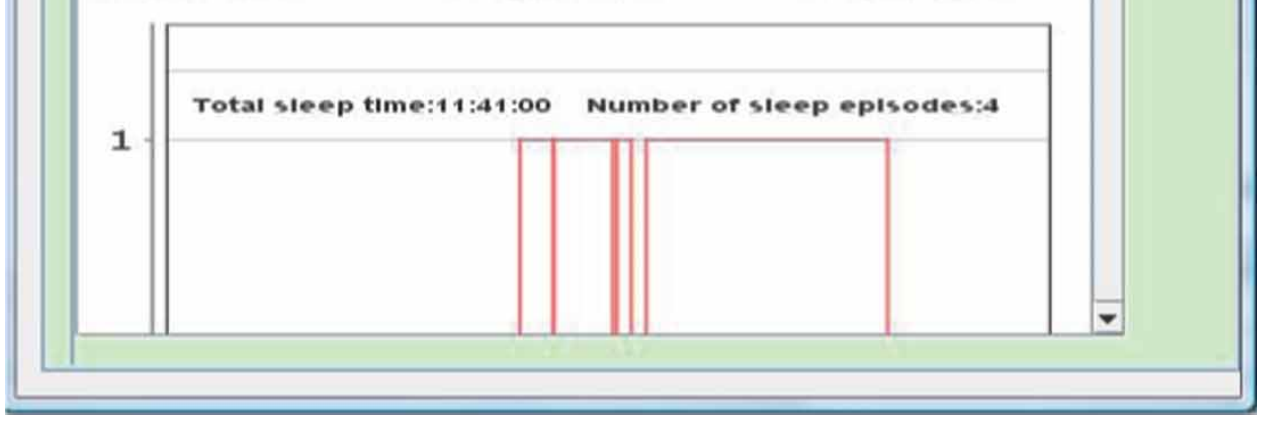

Figure 10. An illustration of a client's weekly sleep pattern. The $x$-axis is the time in $24 \mathrm{~h}$ from 12.00 o'clock to 12.00 o'clock.

and at the time when we were defining the concept, we used simulated scenarios with avatars to stimulate discussion with the partner organisations (Housing Association and Social and Health Care Trusts) on the type of situations we wanted to focus our attention on. Figure 12 shows some of these situations we considered, and Table 2 summarises some of the main scenarios to consider as a result of this process.

One focus group with potential users was organised to gather qualitative feedbacks about the overall system once a full working prototype was available with the final architecture. A range of people interested in the support of people with dementia and their carers was invited to attend a workshop organised with $\mathrm{AgeNI}^{4}$ on 17 June
2011 in order to gather their views on technology and on NOCTURNAL. The workshop was promoted as exploring 'technology-based services supporting older people at night time'. Nine participants (four people with dementia and five carers) were given background to the project and the workshop goals. Two questionnaires were provided, all anonymous, and the process monitored by AgeNI. The first questionnaire (see Table 3) given to the attendees before introducing further the concept of NOCTURNAL indicated that a substantial percentage have interrupted sleep and that needed reading or listening to music and they also indicated that sometimes they would not be able to go back to sleep. A video developed by the project was shown (available from YouTube ${ }^{5}$ ). The second questionnaire (see 


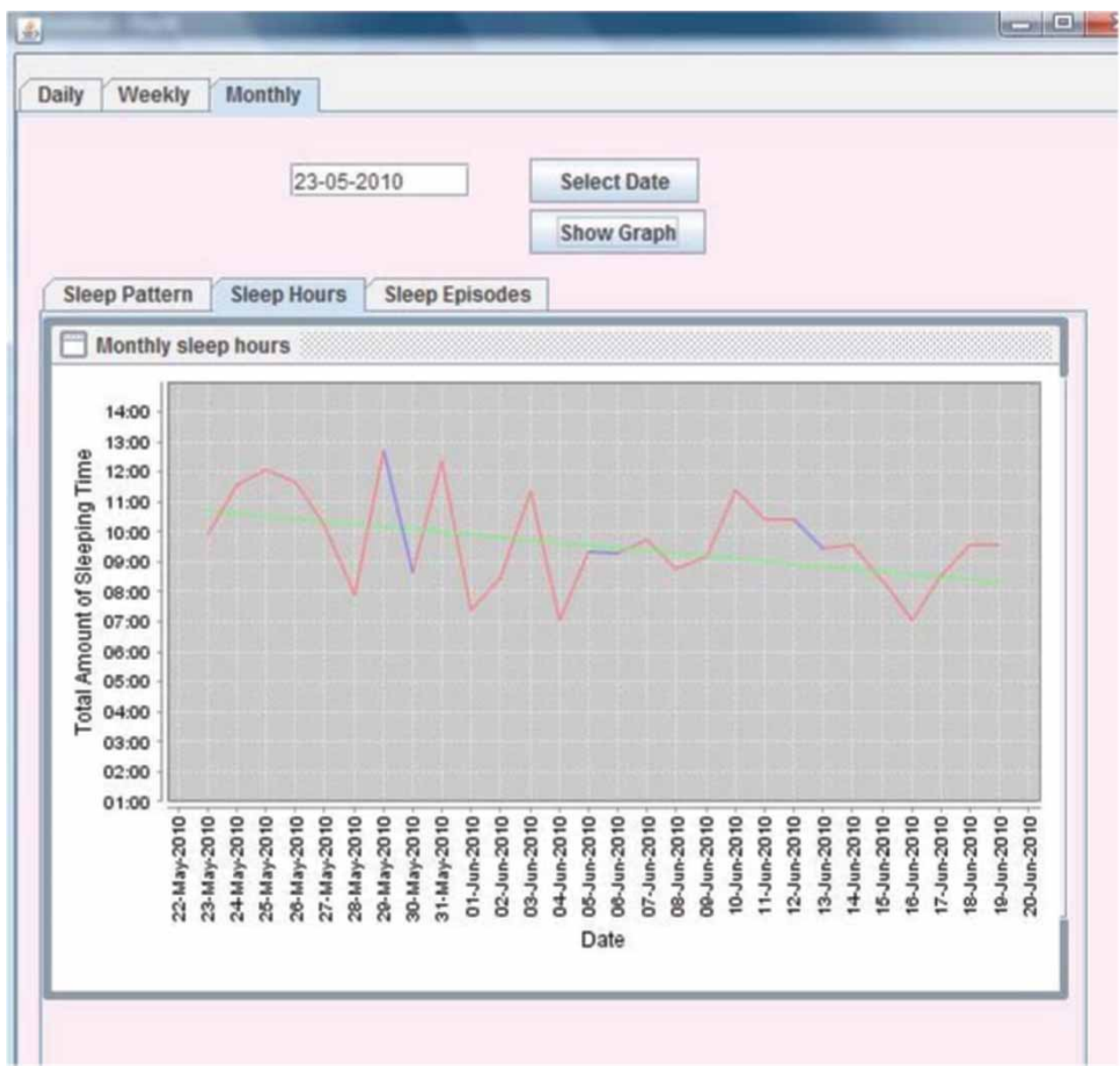

Figure 11. An illustration of a client's monthly sleep hours. The $x$-axis is the date. The $y$-axis indicates the total sleep time in hours. The straight line in the middle indicates the trend of the sleep hour changes during the four weeks.
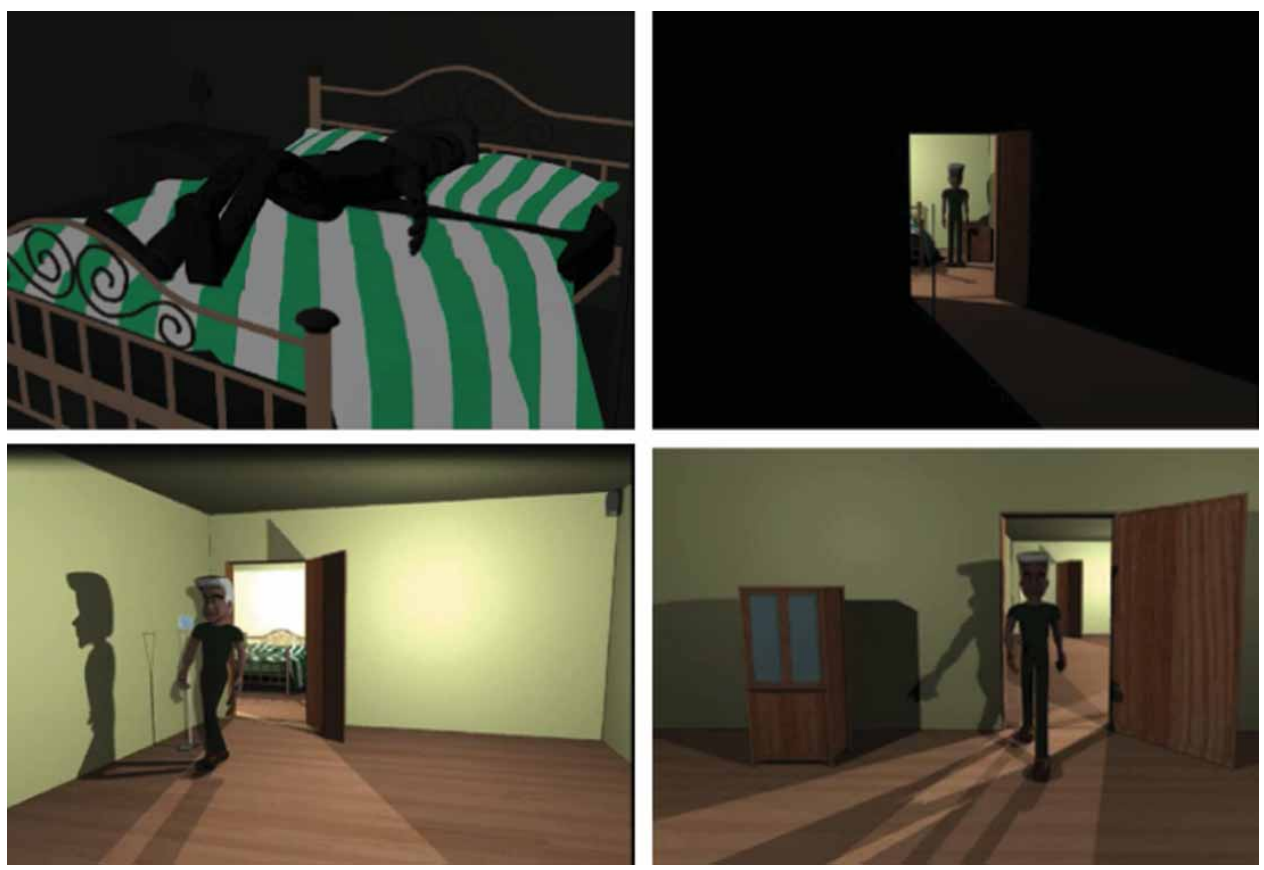

1536

Figure 12. Scenarios explored through prototype. 
Table 2. Scenarios likely to require intervention.

\begin{tabular}{|c|c|c|}
\hline State & Identified by ... & Suggested therapy \\
\hline Restful sleep & $\begin{array}{l}\text { Bed sensor going on and remaining on for the period } \\
\text { of sleep }\end{array}$ & None \\
\hline Restless sleep & $\begin{array}{l}\text { Frequent, short duration on/off events for bed sensor } \\
\text { (and possibly PIR) during the main sleep period }\end{array}$ & Play music at a low level \\
\hline Exiting bed & $\begin{array}{l}\text { Bed sensor activated goes off for longer than } 60 \mathrm{~s} \text {. } \\
\text { Bedroom PIR active }\end{array}$ & $\begin{array}{l}\text { Raise bedroom lights to } 25 \% \text {. Use audio and visual } \\
\text { therapy. Rise/reduce lights according to client's } \\
\text { reaction }\end{array}$ \\
\hline Entering bed & Bed sensor going on for more than $60 \mathrm{~s}$ & $\begin{array}{l}\text { Monitor client's status through bed side light switch, } \\
\text { dim lights if needed }\end{array}$ \\
\hline Exiting bedroom & $\begin{array}{l}\text { Bed sensor and bedroom PIR going off and hall PIR } \\
\text { going on }\end{array}$ & $\begin{array}{l}\text { Dimming lights. Monitor for bathroom PIR to manage } \\
\text { bathroom light. Reverse process when returning } \\
\text { from bathroom to bedroom }\end{array}$ \\
\hline Entering bedroom & Bedroom PIR on. Hall PIR off & \\
\hline Falling asleep & No bed sensor off in previous $X$ min & \\
\hline Awakening & Bed sensor off $<60$ s following restful sleep period & \\
\hline
\end{tabular}
requent, short duration on/off events for bed senso

Raise bedroom lights to $25 \%$. Use audio and visual therapy. Rise/reduce lights according to client's

Table 3. Questionnaire 1 (views on 'night time') used in AgeNI Workshop before introducing the NOCTURNAL concept.

(1) At night time, I normally sleep... (tick one box only) Very badly $\square$ Quite badly $\square$ Quite well $\square$ Very well

(2) I normally sleep for this number of hours... (tick one box only) $\square$ Less than $4 \square 4-6 \square 7-8 \square$ Over 8

(3) My sleep is normally... (tick one box only) $\square$ Very interrupted $\square$ Quite interrupted $\square$ Quite uninterrupted $\square$ Very uninterrupted

(4) When I go to bed, to help me sleep, I... (tick any that apply) $\square$ Read $\square$ Watch TV $\square$ Listen to music $\square$ Other

(5) If I waken up during the night, I fall asleep again... (tick one box only) $\square$ Never $\square$ Sometimes $\square$ Often $\square$ Always

(6) If I waken during the night, and if I cannot sleep I... (tick any that apply) $\square$ Read $\square$ Watch TV $\square$ Listen to music $\square$ Other

Table 4. Questionnaire 2 (views on 'NOCTURNAL'), questionnaire after introducing the NOCTURNAL concept.

(1) What do you think about the concept and idea of NOCTURNAL? $\square$ Very poor $\square$ Quite poor $\square$ Quite good $\square$ Very good

(2) What do you think about the concept for people with dementia? $\square$ Very inappropriate $\square$ Inappropriate $\square$ Appropriate $\square$ Very appropriate

(3) What do you think about the concept for older people? $\square$ Very inappropriate $\square$ Inappropriate $\square$ Appropriate $\square$ Very appropriate

(4) Feature I would value: $\square$ Automatic lights $\square$ Photos $\square$ Listen to music $\square$ Other

(5) Useful feature for people with dementia: $\square$ Reminiscing with music $\square$ Reminiscing with photos $\square$ Therapeutic impact $\square$ Lighting guidance

(6) Using the NOCTURNAL system would be... $\square$ Very difficult $\square$ Difficult $\square$ Quite easy $\square$ Easy

Table 4) given to the participants focused on NOCTURNAL and the potential of the system to help them during the night.
Most of the participants found that the overall concept was good. They also found that the concept was very appropriate for older people, including for those with dementia. The features they found the most useful in general were light management followed by pictures and music. The feature of reminiscence with music and pictures was of special interest for people with dementia.

An evaluation was conducted in an enclosed residential accommodation for elderly people, some of which have early stages of dementia. This assessment was conducted from 9 to 20 December 2011 at the facilities of St. Paul's, a residential accommodation run by the company Praxis in jurisdiction of the South Eastern Health and Social Care Trust, in the city of Lisburn, Northern Ireland. The assessment was conducted simultaneously in five independent flats. These were different from the 10 houses which were used in previous stages of the project with the early versions of the infrastructure. This section describes the case of an exemplar client we will call Sam. The data accumulated indicated approximately 300 restlessness episodes, 86 on the 11 December alone, half of those within the 6:45-7:36 period. Similar and consistent data were recorded in relation to bed occupancy episodes showing a correlation between restlessness and the number of times Sam got up from bed and the time he spent out of bed both in a single episode and cumulatively. There were two episodes of wandering, one on the 11th and another on the 12th of December. The system delivered interventions through the tablet PC (15 instances) and through the management of lights (70 in total). Figure 13 shows the cumulative of interventions in that period. The system generated an alert on the 12 December 2011, 07:17, to be sent to the Housing Association after sensing the client was not responding to the interventions from the system. We were able to check, given the conditions, the alert was a genuine one.

All the shorter evaluations we conducted of the different versions of the system provided different valuable 


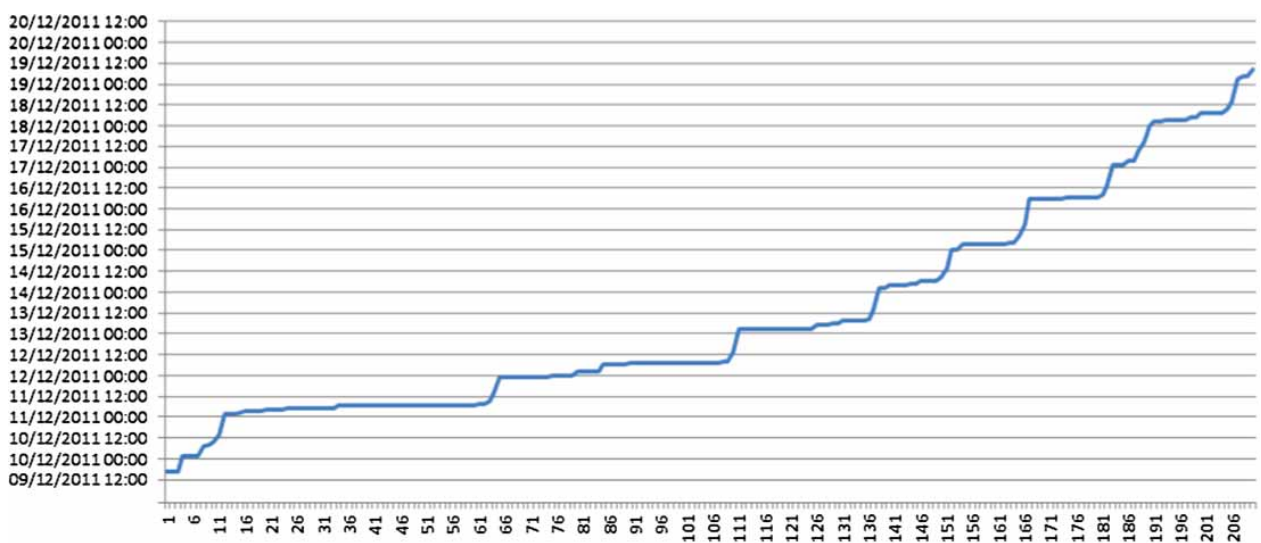

Figure 13. Interventions delivered for 'Sam' at St. Paul's.

information about different aspects of the system. For example, although the first assessment based on the ADLife technology uncovered the need to change the platform to gain independence in the building of the product it also informed us about how to design the different interfaces. The assessment of the second version of the infrastructure based on X10 technology uncovered limitations of that technology for this specific project and the need to incorporate Zwave technology even if that implied a slightly higher cost. The final validation described above was very satisfactory in the sense the system performed as expected and satisfied all the requirements, including providing accurate detection of interesting situations without affecting the normal daily living routine of the person receiving care.

\section{Summary of contributions, conclusions and new directions}

In the NOCTURNAL project, software has been used to assess a client's behaviour and sleep pattern at night, in order to influence an appropriate intervention. Important considerations addressed were:

- user requirements, as addressed by consultation with AgeNI as part of a UCD;

- validation of the software, in order that unsafe conditions could not be allowed and

- assessment of functionality including the contextaware element.

These issues are key to successful adoption. However, we are also aware that the system has to work in association with any existing care monitoring package, so an incremental approach to deployment has been utilised. A safety net must be in place and technology is deployed (Augusto et al. 2011). As appropriate to night time, the research has initially focused on sleep patterns and wandering.

At night, a person with dementia is often likely to be confused and disorientated as they awake from sleep. It can be argued that for them a need for assistive technology may be as or indeed more important as those that lead to the development of assistive technology to support independent living during daylight time. The opportunities to manage risk scenarios afforded by technology may be a key factor in sustaining people at home at a critical point.

The opportunities for research for nocturnal care of people with dementia using holistic assistive technologies are for more specialised algorithms; specially designed interventions that provide therapeutic support to people to reduce anxiety through a multimedia device; and sophisticated guidance, through the use of lightning. This system differs from previous approaches providing a more holistic and extensible framework. NOCTURNAL combines cost-effective infrastructure supported by intelligent agents which can detect and act upon meaningful situations.

Of course, after the initial assessment, further end user validation of the service solution will be required in terms of larger numbers of end users and longer duration of use, in order to assess the scope and amount of any benefit.

\section{Acknowledgements}

The NOCTURNAL team wishes to recognise the highly valuable input that several organisations and individuals have made to the realisation and success of the project. TSB and EPSRC funded the project through Call 1 of the Ambient Assisted Living Program (ALIP I). The Northern Social and Health Care Trust and Southeastern Social and Health Care Trust, both from Northern Ireland, in collaboration with Praxis, provided important support facilitating the identification of suitable clients. Fold Housing Association was our most important partner and provided infrastructure support as well as fundamental human resources and guidance in delivering services to the community. We are deeply thankful to those who tried the system themselves and their circle of carers who provided such a valuable input along the entire project.

\section{Notes}

1. Fold Housing Association (http://www.foldgroup.co.uk/), a notfor-profit organisation delivering Telecare/Telehealth services to UK/Ireland. 
2. http://www.infj.ulst.ac.uk/ jcaug/m.pdf(see comments inserted providing explanation of the model).

3. PIR is an acronym of Passive InfraRed Sensor

4. www.ageuk.org.uk/northern-ireland/

5. http://www.youtube.com/watch?v=pNh8AlZ-8Wk

\section{References}

Adlam, T., et al., 2004. The installation and support of internationally distributed equipment for people with dementia. IEEE Transactions on Information Technology in Biomedicine, 8 (3), 253-257.

Aldridge, D., 2000. Music therapy in dementia care. London: Jessica Kingsley.

Alzheimer's Society, 2011. Available from: http://www.alz.org/ care/alzheimers-dementia-wandering.asp [Accessed July 2012].

Augusto, J.C., 2009. Increasing reliability in the development of intelligent environments. Proceedings of 5th international conference on intelligent environments (IE09), Barcelona, pp. 134-141.

Augusto, J.C., et al., eds., 2012. Handbook on ambient assisted living - technology for healthcare, rehabilitation and wellbeing. Volume 11 of the ambient intelligence and smart environments series, Book Series. IOS Press.

Augusto, J.C. and McCullagh, P., 2007. Ambient intelligence: concepts and applications. International Journal on Computer Science and Information Systems, 4 (1), 1-28.

Augusto, J.C., McCullagh, P., and Augusto-Walkden, J.-A. Living without a safety net in an intelligent environment. ICST Transactions on Ambient Systems, 1 (1). Available from: http://eudl.eu/doi/10.4108/trans.amsys.2011.e6 (Published by ICST).

Beyer, H. and Holtzblatt, K., 1998. Contextual design: defining customer-centered systems. San Francisco, CA: Morgan Kaufmann

Bødker, S., et al., 1993. The AT project: practical research in cooperative design. Aarhus, Denmark: Department of Computer Science, Aarhus University, DAIMI No. PB-454.

Brewer, D., 2013. Home automation made easy: do it yourself know how using UPB, Insteon, X10 and Z-Wave. QUE.

Car, J., 2012. Telehealth for long term conditions. BMJ, 344. doi: $10.1136 / \mathrm{bmj} . \mathrm{e} 4201$

Carswell, W., et al., 2009. A review of the role of assistive technology for people with dementia in the hours of darkness. Technology and Health Care, 17 (4), 281-304.

Consolvo, S., et al., 2008. Flowers or a robot army?: encouraging awareness \& activity with personal, mobile displays. Proceedings of the 10th international conference on ubiquitous computing, 21-24 September, Seoul, Korea.

Daniel, K.M., Cason, C.L., and Ferrell, S., 2009. Emerging technologies to enhance the safety of older people in their homes. Geriatric Nursing, 30 (6), 384-389.

Davies, R., et al., 2009. A user-driven approach to develop a cognitive prosthetic to address unmet needs of people with mild dementia. Journal of Pervasive and Mobile Computing, 5 (3), 253-267.

Department of Health Whole System Demonstrator Programme: Headline Findings, December 2011. Crown, 5-Dec-2011, 16972 [online]. Available from: http://www.dh.gov.uk/en/ Publicationsandstatistics/Publications/PublicationsPolicy AndGuidance/DH_131684 [Accessed July 2012].

Gil, N., et al., 2007. Data visualization and data mining technology for supporting care for older people. Proceedings of the 9th international ACM SIGACCESS conference on computers and accessibility, Tempe, AZ, pp. 139-146.

Gornall, J., 2012. Does telemedicine deserve the green light? BMJ, 345. doi:10.1136/bmj.e4622

Hermans, D.G., Htay, U.H., and McShane, R., 2007. Nonpharmacological interventions for wandering of people with dementia in the domestic setting. Cochrane Database System Review 1, CD005994

Holzmann, G.J., 2003. The SPIN model checker: primer and reference manual. Reading: Addison-Wesley.

ISO-13407, 1999. Human-centred design processes for interactive systems.

Kerr, B., Cunningham, C., and Martin, S., 2010. Telecare and dementia - using telecare effectively in the support of people with dementia. Scottish Government: Joint Improvement Team. Available from: http://www.jitscotland.org.uk/ publications-1/telecare/ [Accessed July 2012].

Kerr, B. and Murray, A., 2011. Telehealthcare and falls using. Telehealthcare effectively in the support of people at risk of falling. Available from: http://www.jitscotland.org.uk/ publications-1/telecare/ [Accessed July 2012].

Kerr, D., Wilkinson, H., and Cunningham, C., 2008. Supporting older people in care homes at night. York, PA: Joseph Rowntree Foundation.

Koenig, S.M., Mack, D., and Alwan, M., 2008. Eldercare technology for clinical practitioners. Aging Medicine, Sleep and Sleep Assessment Technologies, 77-120.

Lewin, K., 1946. Action research and minority problems. Journal of Social Issues, 2 (4), $34-46$.

Limb, M., 2012. NHS boards see telehealth only as a means of saving money, warns expert. BMJ, 345. doi:10.1136/ bmj.e4633

McCullagh, P., et al., 2009. State of the art on night-time care of people with dementia. Proceedings of the conference on assisted living. London: IET.

McCullagh, P.J., et al., 2010. Nocturnal sensing and intervention for assisted living of people with dementia. In: D. Lai, R. Begg, and M. Palaniswami, eds. Healthcare sensor networks-challenges towards practical application. Taylor and Francis/CRC Press.

Nikamalfard, H., et al., 2011. A sleep pattern analysis and visualization system to support people with early dementia Proceedings of Pervasive Health (PH'11), Dublin, Ireland, pp. 510-513.

Norman, D., Miller, J., and Henderson, A., 1995. What you see, some of what's in the future, and how we go about doing it: $\mathrm{HI}$ at apple computer. Proceedings of CHI'95, Denver, CO.

Prince, M. and Jackson, J., eds., 2010. Alzheimer's Disease International World Alzheimer Report 2009. ADI.

Robinson, L., et al., 2006. A systematic literature review of the effectiveness of non-pharmacological interventions to prevent wandering in dementia and evaluation of the ethical implications and acceptability of their use. Health Technology Assessment, 10 (26), 1-124.

Rowe, M.A., Kairalla, J.A., and McCrae, C.S., 2010. Sleep in dementia caregivers and the effect of a nighttime monitoring system. Journal of Nursing Scholarship, 42 (3), 338-347.

Rubin, J., 1994. Handbook of usability, how to plan, design and conduct effective tests. New York: John Wiley \&Sons.

Sade Laja, 2012. Available from: http:/www.guardian.co.uk/ healthcare-network/2011/mar/18/northern-irelandtelehealth-contract [Accessed July 2012].

Scarmeas, N., et al., 2007. Disruptive behavior as a predictor in Alzheimer disease. Archives of Neurology, 64 (12), 1755-1761. 
1921 UK National Statistics Guide to Older People, 2012. Available from: http://www.statistics.gov.uk/hub/population/ageing/ older-people [Accessed July 2012].

Wang, H., et al., 2010. McSorley 'Monitoring and Analysis of Sleep Pattern for People with Early Dementia'. 1st workshop on knowledge engineering, discovery and dissemination in health (KEDDH'10). Proceedings of 2010 IEEE international conference on bioinformatics and biomedicine workshops, 18-21 December 2010, Hong Kong, China, pp. 405-410.

Wojciechowski, M. and Xiong, J., 2008. A user interface level context model for ambient assisted living. Smart Homes and Health Telematics, 105-112 (Online).

Wolkove, N., et al., 2007. Sleep and aging: 1. Sleep disorders commonly found in older people. CMAJ, 176 (9), 1299-1304. 